\title{
Lanthanoid Element Recognition on Surface-Imprinted Polymers Containing Dioleylphosphoric Acid as a Functional Host
}

\author{
Kazuya Uezu, ${ }^{*} 1^{\dagger}$ Tamaki Kuwabara, ${ }^{* 2}$ Masahiro Yoshida, ${ }^{* 3}$ Masahiro Goto,*2 \\ and Shintaro FURUSAKI ${ }^{* 4}$ \\ *1 Department of Chemical Processes and Environments, Faculty of Environmental Engineering, \\ The University of Kitakyushu, Hibikino, Kitakyushu 808-0135, Japan \\ *2 Department of Applied Chemistry, Graduate School of Engineering, Kyushu University, \\ Hakozaki, Fukuoka 812-8581, Japan \\ *3 Department of Applied Chemistry and Chemical Engineering, Kagoshima University, \\ Kagoshima 890-0065, Japan \\ *4 Department of Applied Life Science, Faculty of Engineering, Sojo University, \\ Ikeda, Kumamoto 860-0082, Japan
}

\begin{abstract}
Surface-imprinted polymers have been newly developed for the separation of lanthanoid elements: i.e. La(III), Ce(III), and Dy(III). The imprinted polymers were prepared by surface template polymerization with dioleylphosphoric acid, which exhibits a high affinity to lanthanoids, as a functional host molecule. Separation behavior of La(III), Ce(III) and Dy(III) was investigated with the imprinted polymers, and the imprinting effect of the polymers was evaluated in comparison with that of the unimprinted polymers and also with a conventional solvent extraction method for the same lanthanoid ions. The results indicate that the increase of selectivity for Dy(III) compared to the rest of the ions by the surface-imprinted polymers originated from a synergistic effect of both the affinity with the functional host molecule in nature and the size exclusion by the cavity formed on the polymer surface.
\end{abstract}

(Received August 9, 2004; Accepted September 6, 2004)

\section{Introduction}

An efficient separation process for lanthanoid elements has been actively studied for the production of novel advanced materials for various electronic, optical, and magnetic devices. Conventional solvent extraction is well-known as an effective method for the separation and concentration of lanthanoid elements on an industrial scale. However, the extraction process requires a large number of stages for a series of mixersettlers to obtain high-purity products, because these elements behave almost identically due to the similarity of the chemical and physical properties among the lanthanoids. Liquid surfactant membranes have been investigated as an advanced solvent-extraction method for separating and concentrating lanthanoids to a high degree. ${ }^{1,2}$ Meanwhile, a columnseparation process using an appropriate stationary phase has a great advantage of high concentration efficiency and simplicity with respect to the equipment and operation. For purifying lanthanoid elements, the separation processes have been widely carried out with the combination of a cation exchanger as a stationary phase and a solution containing a chelating reagent as a selective mobile phase. However, when highly selective materials are available as the stationary phase in the column system, diluted mineral acids can be used as eluents in place of expensive chelating reagents.

\footnotetext{
† To whom correspondence should be addressed.

E-mail: uezu@env.kitakyu-u.ac.jp
}

Molecular imprinting is a technique used for preparing polymeric materials that are capable of high molecular recognition..$^{3-6}$ This method usually involves the cross-linking of functional monomers in the presence of template organic molecules or ions by radical polymerization, followed by removal of the target molecules. The imprinted polymers selectively rebind with the template molecules or ions in a mixture of chemical species. The great advantage of this selfassembly approach to form specific recognition sites stems from its generality and relative simplicity. Molecular imprinting has now been successfully applied to create recognition sites in synthetic polymers for a variety of molecules: e.g., nucleotide bases, ${ }^{7,8}$ steroid hormones, ${ }^{9}$ and dipeptide derivatives. ${ }^{10-12}$

We have developed a novel molecular imprinting technique, called "surface template polymerization" (Fig. 1). The method allows one to overcome the following fundamental drawbacks of conventional imprinted polymers that stem from the formation of recognition sites within the hydrophobic polymer matrix: i.e. (1) rebinding kinetics is very slow; (2) it is difficult to handle water-soluble templates, such as metal ions and biological components like proteins. Surface-imprinted polymers are prepared by emulsion polymerization utilizing a functional host molecule, an emulsion stabilizer, a polymer matrix-forming monomer, and a print molecule. A functional host molecule, which is amphiphilic in nature, forms a complex with a print molecule at the interface of emulsions, and thusformed complex remains at the reaction surface. After the matrix is polymerized, the coordination structure is eventually "imprinted" on the polymer surface. We succeeded to prepare 


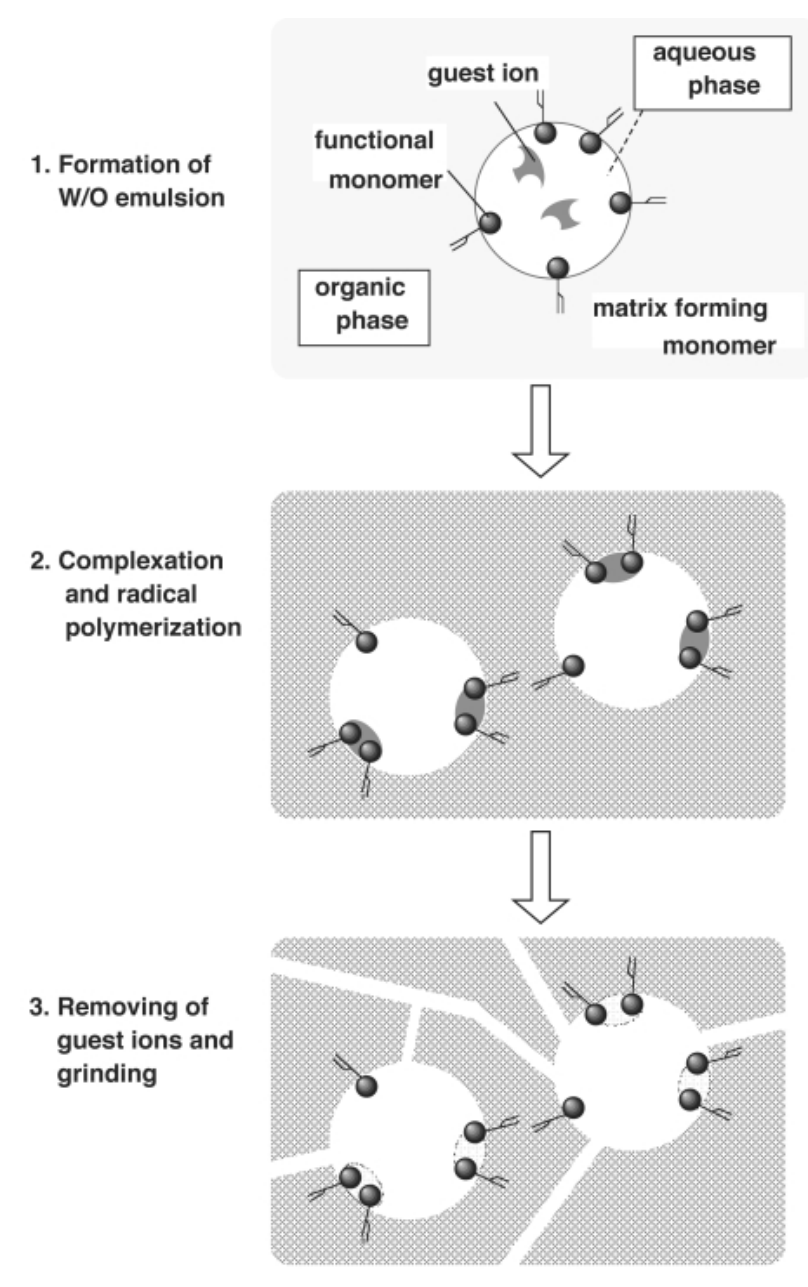

Fig. 1 Schematic illustration of surface template polymerization with W/O emulsions.

surface-imprinted polymers for transition-metal ions, ${ }^{13-15}$ lanthanoid elements, ${ }^{16}$ amino acid derivatives, ${ }^{17}$ nucleotides, ${ }^{18}$ and artificial enzyme. ${ }^{19,20}$ The zinc-ion surface-imprinted microspheres presented an advantage for column separation between zinc and copper ions, compared to the conventional chelating resin. ${ }^{21} \quad$ Furthermore, we clarified that the requirements for designing functional hosts are a strong binding ability with a target molecule and high interfacial activity. ${ }^{13-15}$ We also showed that another important criteria is the rigidity of the polymer matrix to strictly immobilize the functional host molecules on the polymer surface, ${ }^{13}$ and investigated the essential factors that affect the characteristics of the polymer matrix in detail. Consequently, an appropriate choice of the preparation conditions, such as a buffer solution, has made it possible to show the imprinting effect with dioleyl phosphoric acid without $\gamma$-ray irradiation. ${ }^{22}$

In the present study, we prepared surface-imprinted polymers for $\mathrm{La}(\mathrm{III}), \mathrm{Ce}(\mathrm{III})$ and $\mathrm{Dy}(\mathrm{III})$ with dioleylphosphoric acid as a functional host molecule, which has an effective functional group in lanthanoid separation. Separations of $\mathrm{La}$ (III), Ce(III) and Dy(III) with imprinted polymers were performed, and the imprinting effect of the polymer was evaluated in comparison with an unimprinted polymer, and also with a conventional solvent-extraction method for the same metal ions. We also discuss the recognition mechanism of lanthanoid(III)-imprinted polymers.
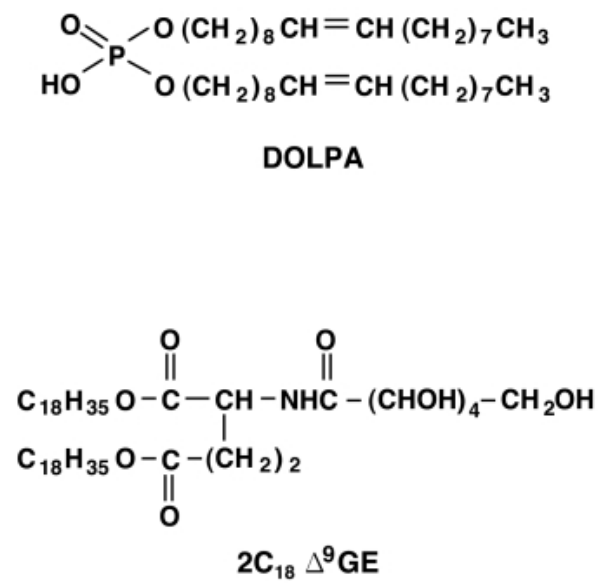

Fig. 2 Structures of dioleylphosphoric acid (DOLPA) and Lglutamic acid dioleylester ribitol $\left(2 \mathrm{C}_{18} \Delta^{9} \mathrm{GE}\right)$.

\section{Experimental}

\section{Materials}

The syntheses of dioleylphosphoric acid (DOLPA) and Lglutamic acid dioleylester ribitol $\left(2 \mathrm{C}_{18} \Delta^{9} \mathrm{GE}\right)$ were reported previously. ${ }^{23,24}$ Divinylbenzene (DVB, Wako Pure Chemical Industries, Ltd.) was used after a treatment with silica gel to remove the inhibitor. Other reagents were of reagent grade. The structures of the functional host and the surfactant used are shown in Fig. 2. Since $2 \mathrm{C}_{18} \Delta^{9} \mathrm{GE}$ is easily dissolved in the organic phase, and its interfacial activity is very high, the surfactant is a suitable emulsion stabilizer for surface template polymerization.

\section{Preparation of lanthanoid(III)-imprinted polymer}

DOLPA (2.9 g, $4.8 \mathrm{mmol})$ and $2 \mathrm{C}_{18} \Delta^{9} \mathrm{GE}(0.15 \mathrm{~g}, 0.18 \mathrm{mmol})$ were dissolved in a $60 \mathrm{~mL}$ toluene-DVB $(1: 2, \mathrm{v} / \mathrm{v})$ solution. An aqueous solution $(30 \mathrm{~mL})$ of $0.010 \mathrm{M}$ lanthanoid(III), whose $\mathrm{pH}$ was adjusted with hydrochloric acid, was added. The mixture was sonicated for 3 min to give a water-in-oil (W/O) emulsion. After the addition of $0.36 \mathrm{~g}(1.4 \mathrm{mmol})$ of $2,2^{\prime}$-azobis $(2,4-$ dimethylvaleronitrile) and $36.56 \mathrm{~g}(28 \mathrm{mmol})$ of DVB, emulsion polymerization was carried out at $55^{\circ} \mathrm{C}$ for $2 \mathrm{~h}$ under a flow of nitrogen. The bulk polymer was dried in vacuo and ground into particles, which were washed with $4.0 \mathrm{M}$ nitric acid to remove the lanthanoid(III), and filtered off. This procedure was repeated until the lanthanoid(III) concentration in the filtrate could not be detected. The lanthanoid(III)-imprinted polymer was dried in vacuo. A reference polymer was prepared similarly, but in the absence of lanthanoid(III). The swelling percentage of the polymers was determined by a volumetric measurement. ${ }^{25}$ Toluene was employed as a swelling solvent.

\section{Solvent extraction of La(III), Ce(III) and Dy(III) by DOLPA}

The organic solution was of $10 \mathrm{mM}$ DOLPA in toluene. The aqueous solution was a mixture of $0.10 \mathrm{mM}$ lanthanoid(III) chlorides $\left(\mathrm{LaCl}_{3}, \mathrm{CeCl}_{3}, \mathrm{DyCl}_{3}\right)$. Its $\mathrm{pH}$ was adjusted to a desired value of between 1 and 5 with hydrochloric acid. A mixture of $10 \mathrm{~mL}$ each of the organic and aqueous solutions was shaken in a thermostatted water bath at $303 \mathrm{~K}$ for $24 \mathrm{~h}$. After phase separation, the equilibrium concentration of lanthanoid(III) in the aqueous phase was determined by ICP atomic emission spectroscopy (Shimadzu, ICPS-5000). 
Table 1 Swelling ratio of polymers in toluene

\begin{tabular}{lc}
\hline \multicolumn{1}{c}{ Polymer } & Swelling ratio, \% \\
\hline Unimprinted polymer for La(III) and Ce(III) & 15 \\
Unimprinted polymer for Dy(III) & 26 \\
La(III)-imprinted polymer & 17 \\
Ce(III)-imprinted polymer & 22 \\
Dy(III)-imprinted polymer & 19 \\
\hline
\end{tabular}

Adsorption of lanthanoid(III) on surface-imprinted polymers

The equilibrium adsorption of lanthanoid(III) by the imprinted polymers was determined batchwise. To the polymer $(0.1 \mathrm{~g})$ was added $5.0 \mathrm{~mL}$ of a $0.10 \mathrm{mM}$ lanthanoid(III) chloride solution. The $\mathrm{pH}$ was adjusted to the desired value between 1 and 5 with hydrochloric acid. The mixture was shaken in a thermostatted water bath at $30^{\circ} \mathrm{C}$ for $24 \mathrm{~h}$. The obtained polymers were filtered with a cellulose nitrate membrane (DISMIC-25, Toyo Roshi Kaisha, Ltd.). The amounts of lanthanoids(III) adsorbed on the polymers were calculated from the decrease in the lanthanoid(III) concentration in the material source, as measured by ICP atomic emission spectrophotometry.

\section{Results and Discussion}

Optimum pH condition in the aqueous phase

The $\mathrm{pH}$ condition in the aqueous phase is one of the dominant factors when preparing highly selective metal ion-imprinted polymers successfully. At a lower $\mathrm{pH}(<1.0)$, recognition sites on the imprinted polymers were not created, due to poor interaction between the functional host molecules and the template lanthanoid ions. At a higher $\mathrm{pH}$, the selectivity of the imprinted polymers decreased due to an increase of the random distributed functional host molecules. Since the optimum $\mathrm{pH}$ condition is dependent on the stability of the metal ionfunctional host complex, we used the solvent-extraction behavior as the criterion for the desirable $\mathrm{pH}$ value during polymerization. The extractability also indicates the degree of interaction between lanthanoid(III) and DOLPA under the minimum geometric constraint. Figure 3 shows the solventextraction behavior of $\mathrm{La}(\mathrm{III}), \mathrm{Ce}(\mathrm{III})$ and Dy(III) with DOLPA. Dy(III) was extracted more than $\mathrm{La}(\mathrm{III})$ and $\mathrm{Ce}(\mathrm{III})$; the extraction behavior of $\mathrm{La}(\mathrm{III})$ was similar to that of $\mathrm{Ce}(\mathrm{III})$. The $\mathrm{pH}$ during polymerization was adjusted to the value at $90 \%$ extraction in a similar way for $\mathrm{Zn}$ (II)-imprinted polymers, i.e. 1.5 for $\mathrm{Dy}(\mathrm{III}) ; 2.3$ for $\mathrm{La}(\mathrm{III})$ and $\mathrm{Ce}(\mathrm{III})$.

\section{Rigidity of the polymer matrix}

The rigidity of the polymer matrix is also important to firmly immobilize the functional hosts. We evaluated the rigidity by utilizing the swelling ratio of the soaked polymer in toluene. Based on the results of $\mathrm{Zn}$ (II)-imprinted polymers, ${ }^{15}$ the minimum requirement to obtain a high template effect is that the swelling ratio of the imprinted polymer is below 30\%. The swelling ratios of lanthanoid(III)-imprinted polymers are summarized in Table 1. All swelling ratios of imprinted and unimprinted polymers are below $30 \%$, while the ratio of $\mathrm{Zn}(\mathrm{II})$ imprinted polymers with DOLPA is much higher than that of unimprinted polymers. ${ }^{13}$ Therefore, the matrix of the lanthanoid(III)-imprinted polymers possesses an appropriate rigidity to strictly fix the functional host molecules. This is due to much fewer inhibitors, such as sodium ions in the buffer

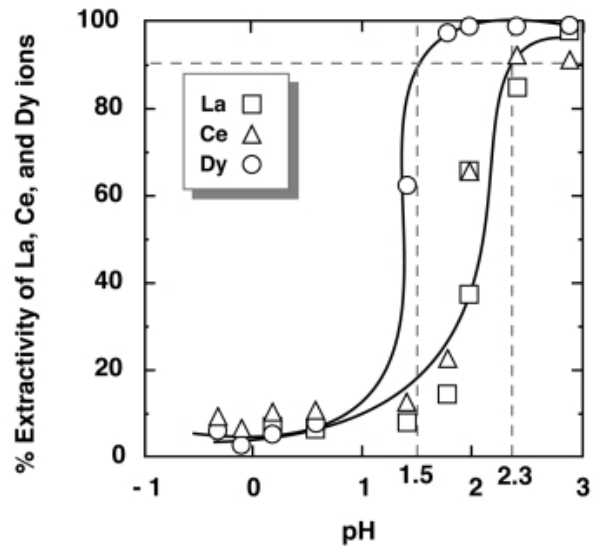

Fig. 3 Solvent-extraction behavior of La(III), Ce(III), and Dy(III) with DOLPA.

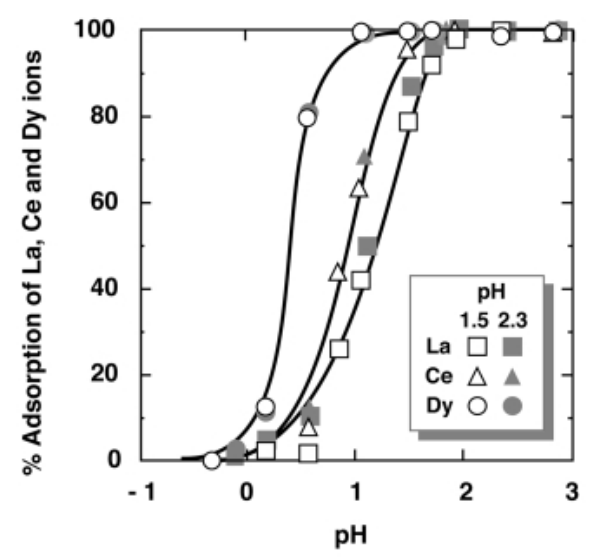

Fig. 4 Adsorption behavior of $\mathrm{La}(\mathrm{III}), \mathrm{Ce}(\mathrm{III})$, and $\mathrm{Dy}(\mathrm{III})$ with unimprinted polymers using DOLPA.

solution for surface template polymerization..$^{22}$

\section{Separation of lanthanoid(III) with surface-imprinted polymers}

Most organophosphate-lanthanoid(III) complexes have a nonacoordination structure, i.e. tricapped trigonal prism coordination in a series of lanthanoids(III). ${ }^{26}$ Thus, size recognition is required to prepare surface-templated polymers for accomplishing an effective separation of lanthanoid elements.

Figure 4 shows the adsorption behavior of $\mathrm{La}(\mathrm{III}), \mathrm{Ce}(\mathrm{III})$ and Dy(III) with unimprinted polymers under different $\mathrm{pH}$ conditions. The $\mathrm{pH}$ values during polymerization were 1.5 for Dy(III) and 2.3 for $\mathrm{La}(\mathrm{III})$ and $\mathrm{Ce}(\mathrm{III})$. No difference between unimprinted polymers prepared at $\mathrm{pH} 1.5$ and 2.3 was observed. Since the $\mathrm{pH}$ value during polymerization does not affect the adsorption ability of unimprinted polymers, the functional host distribution was almost the same in both unimprinted polymers within this $\mathrm{pH}$ range. The selectivity of unimprinted polymers was similar to that of solvent extraction with DOLPA. This poor selectivity is due to the random distribution of functional hosts on the polymer surface.

Figure 5 exhibits the $\mathrm{pH}$ dependence of the adsorption of $\mathrm{La}(\mathrm{III}), \mathrm{Ce}(\mathrm{III})$ and Dy(III) on the Dy(III)-imprinted polymer. The percent adsorption was enhanced with increasing the $\mathrm{pH}$ for all lanthanoid(III) ions. This result suggests that the adsorption behavior proceeds through an ion-exchange mechanism. The 


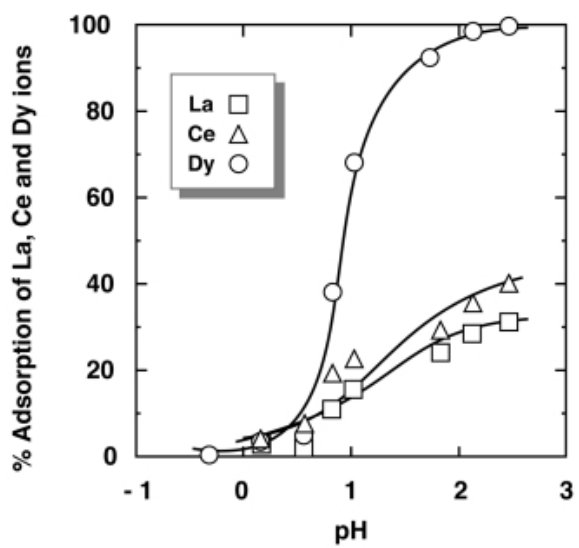

Fig. 5 Adsorption behavior of $\mathrm{La}(\mathrm{III}), \mathrm{Ce}(\mathrm{III})$, and $\mathrm{Dy}(\mathrm{III})$ with Dy(III)-imprinted polymers using DOLPA.

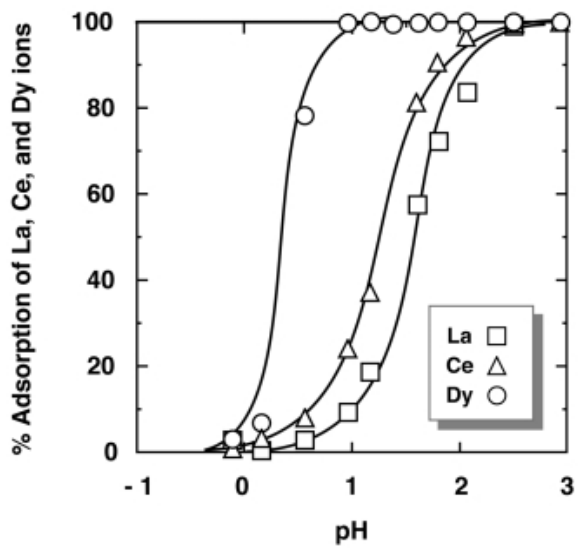

Fig. 6 Adsorption behavior of $\mathrm{La}(\mathrm{III}), \mathrm{Ce}(\mathrm{III})$, and Dy(III) with $\mathrm{La}$ (III)-imprinted polymers using DOLPA.

imprinted polymer, however, adsorbed Dy(III) much more effectively than $\mathrm{Ce}(\mathrm{III})$ and $\mathrm{La}(\mathrm{III})$ over the entire $\mathrm{pH}$ range. In the case of adsorption by the unimprinted polymer, prominent selectivity for Dy(III) was not observed compared to that by the imprinted polymer (Fig. 4). The ionic radii of Dy(III), Ce(III) and $\mathrm{La}(\mathrm{III})$ in nonacoordinate are $1.083,1.196$ and $1.216 \AA$, respectively $;^{27}$ the selectivity for Dy(III) is controlled by the size of the cavity that functional host molecules have created on the surface of the polymers. On the other hand, no imprint effect was observed in an adsorption test using the $\mathrm{La}$ (III)-imprinted polymer (Fig. 6). This indicates that $\mathrm{Ce}$ (III) and Dy(III) can invade into the La(III)-fitted cavity and adhere to the recognition sites, because their ionic radii are smaller and their affinity with the functional host molecules in nature is higher than that of $\mathrm{La}(\mathrm{III})$. The imprinted polymer for $\mathrm{Ce}(\mathrm{III})$, whose ion radius is intermediate between La(III) and Dy(III), showed an intermediate selectivity among three metal ions; i.e. Dy(III) was still significantly adsorbed, while the adsorption of $\mathrm{La}$ (III) decreased on the Ce(III)-imprinted polymers (Fig. 7). This result also supports the effect of ion size exclusion. When the smallest ion Dy(III) was imprinted on the polymer surface, $\mathrm{La}(\mathrm{III})$ and $\mathrm{Ce}(\mathrm{III})$, which have a larger ionic size than Dy(III), cannot invade the cavity due to the size-exclusion effect. Therefore, the Dy(III)-imprinted polymer showed the highest template effect in the lanthanoid separation test. Based on the results, the improvement of selectivity for lanthanoid(III) by

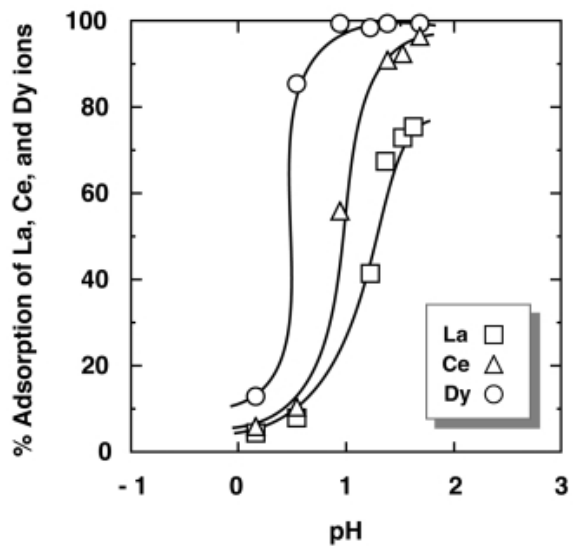

Fig. 7 Adsorption behavior of $\mathrm{La}(\mathrm{III}), \mathrm{Ce}(\mathrm{III})$, and Dy(III) with Ce(III)-imprinted polymers using DOLPA.

surface-imprinted polymers originates from a synergistic effect of the affinity with a functional host molecule in nature, and the size exclusion by the cavity formed on the polymer surface.

\section{Conclusions}

We have developed lanthanoid ion-imprinted polymers by surface template polymerization for the separation of lanthanoid elements, i.e. La(III), Ce(III), and Dy(III). A Dy(III)-imprinted polymer was shown to exhibit a tremendously high selectivity towards Dy(III) ions over $\mathrm{La}(\mathrm{III})$ and $\mathrm{Ce}(\mathrm{III})$ ions. We found that there are two important factors to obtain high selectivity and an imprint effect towards a target lanthanoid: a high affinity to the target ion and a size-exclusion effect, which stems from imprinted sites formed by functional molecules. A high selectivity was observed by an imprinted polymer in which the above two factors were satisfied for the preparation.

\section{Acknowledgements}

This work was supported in part by a Grant-in-Aid for Scientific Research (No. 14550752, 16560661) from the Ministry of Education, Culture, Sports, Science \& Technology of Japan. Financial support by the Japan Securities Scholarship Foundation is acknowledged.

\section{References}

1. K. Uezu, M. Goto, S. Irie, K. Ikemizu, and F. Nakashio, Sep. Sci. Technol., 1995, 30, 3325.

2. K. Uezu, S. Irie, O. Yoshimura, M. Goto, and F. Nakashio, Trans. IchemE PartA, 1997, 75, 513.

3. G. Wulff and K. Knorr, Bioseparation, 2002, 10, 257.

4. K. Haupt and K. Mosbach, Biochem. Soc. Trans., 1999, 27, 344.

5. M. Komiyama, T. Takeuchi, T. Mukawa, and H. Asanuma, "Molecular Imprinting", 2002, Wiley-VCH, Weinheim.

6. K. Uezu, M. Yoshida, M. Goto, and S. Furusaki, CHEMTECH, 1999, 29, 12.

7. D. A. Spivak and K. J. Shea, Anal. Chim. Acta, 2001, 435, 65.

8. J. Matsui, Y. Tachibana, and T. Takeuchi, Anal. Commun., 1998, 35, 225. 
9. C. Alexander, C. R. Smith, M. J. Whitcombe, and E. N. Vulfson, J. Am. Chem. Soc., 1999, 121, 6640.

10. B. R. Hart and K. J. Shea, Macromolecules, 2002, 35, 6192.

11. H. Asanuma, K. Kajiya, T. Hishiya, and M. Komiyama, Chem. Lett., 1999, 665.

12. K. Yano, T. Nakagiri, T. Takeuchi, J. Matsui, K. Ikebukuro, and I. Karube, Anal. Chim. Acta, 1997, 357, 91.

13. K. Uezu, H. Nakamura, J. Kanno, T. Sugo, M. Goto, and F. Nakashio, Macromolecules, 1997, 30, 3888

14. K. Uezu, M. Goto, and F. Nakashio, "ACS Symposium Series 703", 1998, American Chemical Society, Washington, D.C., 278.

15. M. Yoshida, K. Uezu, M. Goto, and S. Furusaki, Macromolecules, 1999, 32, 1237.

16. K. Araki, M. Yoshida, K. Uezu, M. Goto, and S. Furusaki, J. Chem. Eng. Jpn., 2000, 33, 665.

17. M. Yoshida, Y. Hatate, K. Uezu, M. Goto, and S. Furusaki, Colloid Surf., 2000, 169, 259.
18. H. Tsunemori, K. Araki, K. Uezu, M. Goto, and S. Furusaki, Bioseparation, 2002, 10, 315.

19. E. Toorisaka, M. Yoshida, K. Uezu, M. Goto, and S. Furusaki, Chem. Lett., 1999, 387.

20. E. Toorisaka, K. Uezu, M. Goto, and S. Furusaki, Biochem. Eng. J., 2003, 14, 85.

21. M. Yoshida, Y. Hatate, K. Uezu, M. Goto, and S. Furusaki, J. Polym. Sci., 2000, 38, 689.

22. K. Uezu, N. Tazume, M. Yoshida, M. Goto, and S. Furusaki, Kagaku Kougaku Ronbunshu, 2001, 27, 753.

23. M. Goto, M. Matsumoto, K. Kondo, and F. Nakashio, $J$. Chem. Eng. Jpn., 1987, 20, 157.

24. M. Goto, K. Kondo, and F. Nakashio, J. Chem. Eng. Jpn., 1989, 22, 79.

25. T. K. Green, J. Kovac, and J. W. Larsen, Fuel, 1984, 63, 935.

26. P. Comba, K. Gloe, K. Inoue, T. Krüger, H. Stephan, and K. Yoshizuka, Inorg. Chem., 1998, 37, 3310.

27. R. Shannon, Acta Crystallogr., 1976, A32, 751. 